\title{
Which Characters of Knowledge-Based Employees Have Higher Turnover Intension in Chinese Culture Industry?
}

\author{
Jing'an Chen \\ Economy Management Department, Southwest Jiaotong University, Chengdu, China \\ Email: cja1964cn@163.com
}

Received April 2014

\begin{abstract}
By use of multiple logistic regression analysis of the questionnaire data of 465 knowledge-based staff in the culture industry of a province in the Western China, the author has found that the three main factors related to job satisfaction and the turnover intention are not simply negatively correlative, which differs from the former classical studies of relationship between job satisfaction and turnover intention. This research has discovered that 1) the factor of career development satisfaction is not predictable on the turnover intention probability; 2) the turnover intention of the knowledge-based staff who have low satisfaction with the job itself is not higher than those who have high satisfaction with their jobs; 3 ) the turnover intention of the staff with low pay satisfaction is lower than those with high pay satisfaction, that is, the knowledge-based employees with higher pay satisfaction have correspondingly higher probability of turnover intention, compared with those with lower pay satisfaction; 4) such covariates as gender, age, educational background, professional title, income level, position, working years, the number of previous work units being considered, all mentioned demographic characteristics above but the income level have no significant influence on turnover intention; the employees with low income levels are more unwilling to leave than those with higher monthly income level.
\end{abstract}

\section{Keywords}

Job Satisfaction, Turnover Intention, Cultural Industry, Western China

\section{Introduction}

In recent years, the rapid development of Chinese culture industry has been accompanied by the increasing turnover of knowledge staff in some cultural enterprises. What are the relationships between the job satisfaction of knowledge staff of those enterprises and their turnover? Is the mode similar to that of the knowledge staff in IT industry, colleges and research institutes? Who have the highest turnover intention among the knowledge staff of cultural industry? All these questions need to be further studied so as to establish a precise early warning system against the resign of knowledge staff and to prevent excessive loss of knowledge staff of culture industry 
in western China.

The research results of most scholars at home and abroad have indicated that job satisfaction and turnover intention are negatively correlated and positively correlated with their tendency of stay; some researchers have even found that there is no significant correlation between job satisfaction and turnover (Porter et al., 1973) [1]. Existing research have shown that there are differences in demographics in terms of job satisfaction. When it comes to the relationship between age and job satisfaction, some studies have found that age and job satisfaction is positively correlated, that is, job satisfaction grows higher with age (Bluedorn, 1982; Martin, 1979), negative correlated (Muchinsky et al., 1978), not significantly correlated (Ronen, 1978; Nassab, 2008). And some other research has proved that the correlation between age and overall job satisfaction is shown as a U-shaped model (Herzberg, Mausner, 1957), inverted U-shaped (Wang Zhigang, Jiang Huiming, 2004), and J-shaped model (Saleh, 1964); as for the correlation between gender and job satisfaction, some experts believe that no simple conclusion can be drawn on the distinction of job satisfaction of men and women (Herzberg, 1957), while Chinese data has shown that female employees have higher job satisfaction than males (Wang Zhigang, Jiang Huiming, 2004), and Ismael \& Richard (1991) has discovered that female teachers have higher job satisfaction than male teachers; the correlation between years of working and job satisfaction remains inconclusive. According to some research, the longer the length of service is, the higher the employees' job satisfaction (Martin, 1979), although some others have proved the job satisfaction of the employees with more years of working is lower than that of those with shorter length of service (Lin Zheng, 1999; Gibson \& Klein, 1970). There is also a study which has found that age only has significant influence on the working relationship of women (Shott, Albright \& Glennon, 1963); the correlation between the degree of education and job satisfaction is uncertain, because experts have argued that they are positively correlated (Shi Pu, 1991), negatively correlated (Blegen \& Muller, 1987) and not significantly correlated (Ding Hong, 1987).

In terms of the research objects of the knowledge staff, we mainly focus on teachers and professors in colleges and universities and the employees of scientific research institutions and IT companies. On the research methods, Chinese scholars used to apply correlation analysis to study the relationship between job satisfaction and turnover intention and have currently employed structural equation model in their analysis. Correlation analysis can only verify the correlation between job satisfaction and turnover intention, but cannot manifest the causality between the two; in essence, structural equation model is the regression analysis of exploratory factor analysis basis which can analyze the causal relationship or path relationship of them but cannot tell the probability of job satisfaction affecting turnover intention. Based on the questionnaires of the knowledge employees in the cultural industry of a province in Western China and PCA (principal component analysis), this study adopts multiple logistic regression model to analyze the degree of probability of work satisfaction affecting the turnover intention. This study takes the knowledge staff in the cultural industry of the western region as the research objects; there-

Shi Yinlei (2007), through relevant analysis, found that all dimensions related to job satisfaction but career development were negatively correlated to the turnover intention. He Guifen (2009) concluded from certain research that the job satisfaction of the employees in IT enterprises had significant negative correlation with their turnover intention and had certain predictive effect on turnover intention; the most important dimension affecting the turnover intention of IT employees is the work content, followed by supervisors' supervision, salary and welfare, role load, role ambiguity and career development successively. Wang Dongqian (2013) believed that the five dimensions related to the job satisfaction of knowledge employees are all significantly negatively correlated to the turnover intention. Among others, leadership management satisfaction had most negative correlation with turnover intention, while individual development satisfaction had least negative correlation with turnover intention. Yang Xiuwei et al. (2005) took teachers in universities and colleges as the objects of study and pointed out that three dimensions of job satisfaction, namely, the work itself, leadership management and interpersonal relationship, had significantly negative influences on turnover intention. Cheng Yu (2010) proved that job satisfaction of IT employees had significantly negative correlation with their turnover intention. Among all dimensions accounting for job satisfaction, satisfaction with the working conditions, leaders behaviors and external reward had significant influences on their turnover intention; He Xiongwei (2009) found that work payoff and work tasks of the work satisfaction had significant influences on the turnover intention of university and college teachers. About the relationship between age and job satisfaction, some studies have found that age is positively correlated with job satisfaction, and the higher one's age, the higher job satisfaction he/she has (Bluedorn, 1982; Martin, 1979), negatively correlated (Muchinsky et al., 1978), and not significantly correlated (Ronen, 1978; Nassab, 2008). And some other research has proved that the correlation between age and overall job satisfaction is shown as a U-shaped model (Herzberg, Mausner, 1957), inverted U-shaped (Wang Zhigang, Jiang Huiming, 2004), and J-shaped model (Saleh, 1964); as for the correlation between gender and job satisfaction, some experts believe that no simple conclusion can be drawn on the distinction of job satisfaction of men and women (Herzberg et al., 1957), while Chinese data has shown that female employees have higher job satisfaction than males (Wang Zhigang, Jiang Huiming, 2004), and Ismael \& Richard (1991) has discovered that female teachers have higher job satisfaction than male teachers; the correlation between years of working and job satisfaction remains inconclusive. According to some research, the longer the length of service is, the higher the employees' job satisfaction (Martin, 1979), although some others have proved the job satisfaction of the employees with more years of working is lower than that of those with shorter length of service (Lin Zheng, 1999; Gibson \& Klein, 1970). There is also a study which has found that age only has significant influence on the working relationship of women (Shott, Albright \& Glennon, 1963); the correlation between the degree of education and job satisfaction is uncertain, because experts have argued that they are positively correlated (Shi Pu, 1991), negatively correlated (Blegen \& Muller, 1987) and not significantly correlated (Ding Hong, 1987). 
fore the research conclusion will further enrich the empirical research results of the relationship between the job satisfaction and turnover intention of Chinese knowledge staff.

\section{Measuring Tools, Sampling Methods and the Demographic Variables of Samples}

\subsection{The Measuring Tools and Credibility}

The Job Satisfaction Survey is based on modified Employee Satisfaction Questionnaire [2] of Tsui (1992) and the Minnesota Satisfaction Questionnaire (MSQ). Likert's Five-Scaling Method is adopted to score the subjects' satisfaction and make evaluation. "1" represents total disagreement, " 5 " strong agreement, the higher the score, the higher the job satisfaction. The Job satisfaction scale overall Cronbach a consistency coefficient is 0.778 , meeting the usually recognized requirement of internal consistency reliability above 0.6 [3].

The turnover intention falls into far from intense, not very intense, common, relatively intense, very intense, and the assignments of the five points with Likert Scale are 1 - 5.

\subsection{Sampling Method}

The Questionnaire takes “Directory of the First Batch of Key Cultural Enterprises of ** Province” as a sample frame, covering such seven industries as cultural tourism industry, publication and distribution industry, film and television industry, entertainment and leisure industry, printing industry, animation game industry and creative design industry. About the definition of knowledge employees, in the actual survey, the data of employees with a junior college degree and above have been collected. 1000 questionnaires have been issued and 546 of them taken back, with a questionnaire recovery rate of $54.6 \%$. The number of effective questionnaires is 465 and the effective questionnaire recovery rate $46.5 \%$.

\subsection{The Demographic Variables of the Samples}

The general information of the demographic statistics of the questionnaires is as follows.

(1) Gender. Male 53.2\%, female 53.2\%.

(2) Age. 25 years old and under constituting 3.9\%, 26 - 30 years old 11.2\%, 31 - 35 years old 15.1\%, 36 - 40 years old $14.1 \%$, 41 to 50 years old $34.6 \%$, 50 years old above $21.0 \%$.

(3) Degree. The subjects with a Doctoral Degree accounting for $1.0 \%$, Masters $15.3 \%$, Bachelors $57.1 \%$ and junior college graduates $26.6 \%$.

(4) Professional title. The subjects with a senior title accounting for $23.8 \%$, intermediate title $33.7 \%$, primary title $9.9 \%$, title to be conferred $32.7 \%$.

(5) Monthly income level. 2000 Yuan and below accounting for 2.6\%, 2001 - 4000 Yuan 29.4\%, 4001 - 6000 Yuan 21.1\%, 6001 - 8000 Yuan 14.9\%, 8001 - 10,000 Yuan 8.2\%, 10001 - 15,000 Yuan 17.0\%, 15,001 - 20,000 Yuan 5.7\%, 20,000 Yuan above 1.0\%.

(6). Position. Marketing 10.0\%, Operating Management28.0\%, Professional Skills 39.5\%, other positions $22.5 \%$.

(7) Years of working. 5 years and below 12.3\%, 6 - 10 years 14.7\%, 11 - 20 years 22.5\%, 21 - 30 years 25.0\%, 31 years above $25.5 \%$.

(8) The number of previous work units. No previous work unit 37.0\%, 1 (22.0\%), 2 (21.5\%), 3 (11.5\%), 4 (3.5\%), 5 and above $3.5 \%$.

\section{Factor Analysis}

\subsection{Factor Analysis Validity Test}

KMO and Bartlett's Test of Sphericity are used to test whether the samples are suitable for factor analysis. The SPSS17.0 analysis results showed that the KMO measure value of the samples is 0.916 , the Approximate Chi-Square value of Bartlett's Test of Sphericity is 2029.539, P value reaches 0.000, so the indicators show that the samples are suitable for factor analysis (see Table 1).

\subsection{Factor Extraction}

According to the rule that the factor feature value is greater than the threshold value of 1 , three common factors 
have been extracted, and the cumulative resolution reached $71.402 \%$, which shows that the overall explanatory power of the common factors is stronger.

\subsection{Factor Induction}

Use Varimax to rotate the factors and determine which factor each item belongs to according to whether the factor loading value of each item reaches 0.5 as the threshold value (see Table 2).

The research based on the factor analysis method has found that the job satisfaction of knowledge staff in the cultural industry includes three main factors: the first main factor is related to the job itself, including reflecting individual professional knowledge level, the opportunities giving play to their specialty, the growth opportunities, reflecting one's value, the creativity and degree of freedom of the job itself, etc.; the second main factor is career development, including the status of cultural industry in the regional industries, the prospects of the industry itself, the prospects of the unit, etc.; the third main factor is the pay, including the competitiveness of the pay, income rationality and pay fairness and so on.

\section{Multiple Logistic Regression Analysis}

On the basis of the above factor analysis results, multiple logistic regression analysis has been made with the work itself, career development and pay factor as explanatory variables, and gender, age, education, income, etc. as control variables, in order to determine the probability of job satisfaction affecting turnover intention.

Table 1. KMO and Bartlett's Test.

\begin{tabular}{|c|c|c|}
\hline \multicolumn{2}{|c|}{ Kaiser-Meyer-Olkin Measure of Sampling Adequacy. } & 0.916 \\
\hline \multirow{3}{*}{ Bartlett's Test of Sphericity } & Approx. Chi-Square & 2029.539 \\
\hline & $\mathrm{df}$ & 105 \\
\hline & Sig. & 0.000 \\
\hline
\end{tabular}

Table 2. Factor loading matrix after rotation.

\begin{tabular}{|c|c|c|c|}
\hline & \multicolumn{3}{|c|}{ Factor } \\
\hline Item & 1 & 2 & 3 \\
\hline You are satisfied with the work environment of your unit. & 0.592 & 0.048 & 0.389 \\
\hline You are satisfied with the degree of freedom and creativity of your work. & 0.722 & 0.102 & 0.448 \\
\hline The post enables you to give play to your operational capability and realize your personal value. & 0.721 & 0.412 & 0.274 \\
\hline Your job can give play to the professional knowledge you have learned. & 0.666 & 0.294 & -0.080 \\
\hline You have many opportunities for personal growth. & 0.735 & 0.238 & 0.351 \\
\hline You take pride in your work. & 0.549 & 0.527 & 0.161 \\
\hline You plan to have long-term career development in ${ }^{* *}$ Province. & 0.170 & 0.825 & 0.294 \\
\hline You plan to have long-term career development in this unit. & 0.243 & 0.855 & 0.226 \\
\hline You are willing to have long-term development in the field of cultural industry. & 0.219 & 0.869 & 0.188 \\
\hline You can feel the joy from work. & 0.537 & 0.566 & 0.192 \\
\hline You current occupation can give play to your specialty and enable you to realize your personal value. & 0.610 & 0.530 & 0.223 \\
\hline The industry you are in is the key industry of ${ }^{* *}$ Province and very promising. & 0.458 & 0.438 & 0.538 \\
\hline You think that your income is acceptable compared with your contribution to the job. & 0.170 & 0.255 & 0.840 \\
\hline Your pay level is higher than the average level of the industry, very competitive. & 0.196 & 0.200 & 0.833 \\
\hline You think that the pay system of your unit is relatively fair. & 0.228 & 0.222 & 0.814 \\
\hline
\end{tabular}




\subsection{Model Test}

Establish a multiple logistic regression model with the work itself, career development and pay factor as explanatory variables and turnover intention as a dependent variable.

“-2LL” Likelihood Chi-Square test. From the initial model to the final model, “-2LL” value reduces by about 70 , and the model has been improved significantly. The probability of the model test sig. value is .000 , which indicates that the model's degree of fitting is good (see Table 3).

\subsection{Probabilistic Forecasting of Job Satisfaction on Turnover Intention}

In the multiple logistic regression model, the four groups of data of turnover intention are compared with the last group with "very intense" turnover intention. From Table 4 "Test of the Multiple Logistic Regression Model”, the following conclusion can be drawn.

(1) There are no significant differences in the influences of the career development factors on the five groups of turnover intention. Compared with the group with "very intense" turnover intention, the significances of the influence probabilities on the other four groups of turnover intention to different extents are all above 0.05. This indicates that at the probability level of 0.05 , the influences of the differences in career development satisfaction on the turnover intention do not cause discrepancy with statistical significance. In the existing research conclu-

Table 3. Model Test.

\begin{tabular}{ccccc}
\hline Model & -2 Log Likelihood & Chi-Square & df & Sig. \\
\hline Intercept Term & 411.677 & & & \\
Final Model & 341.901 & 69.776 & 12 & .000 \\
\hline
\end{tabular}

Table 4. Test of the multiple logistic regression model.

\begin{tabular}{|c|c|c|c|c|c|c|c|c|c|}
\hline \multirow[t]{2}{*}{$\begin{array}{c}\text { Turnover } \\
\text { Intention (a) }\end{array}$} & & \multirow[t]{2}{*}{ B } & \multirow[t]{2}{*}{ Standard Error } & \multirow[t]{2}{*}{ Wald Value } & \multirow[t]{2}{*}{$\begin{array}{c}\text { Degree of } \\
\text { Freedom }\end{array}$} & \multirow[t]{2}{*}{ Significance } & \multirow[t]{2}{*}{$\begin{array}{l}\text { Forecasting } \\
\text { Probability }\end{array}$} & \multicolumn{2}{|c|}{$\begin{array}{l}\text { 95\% Confidence } \\
\text { Interval for } \operatorname{Exp}(\mathrm{B})\end{array}$} \\
\hline & & & & & & & & $\begin{array}{l}\text { Lower } \\
\text { Bound }\end{array}$ & $\begin{array}{l}\text { Upper } \\
\text { Bound }\end{array}$ \\
\hline \multirow[t]{4}{*}{ Far from Intense } & Intercept Term & 3.453 & 0.755 & 20.912 & 1 & 0.000 & & & \\
\hline & The Work Itself & 1.485 & 0.588 & 6.387 & 1 & 0.011 & 4.416 & 1.396 & 13.972 \\
\hline & $\begin{array}{c}\text { Career } \\
\text { Development }\end{array}$ & 0.445 & 0.526 & 0.714 & 1 & 0.398 & 1.560 & 0.556 & 4.377 \\
\hline & Pay & 1.267 & 0.508 & 6.219 & 1 & 0.013 & 3.551 & 1.312 & 9.615 \\
\hline \multirow[t]{4}{*}{ Not very Intense } & Intercept Term & 2.866 & 0.763 & 14.119 & 1 & 0.000 & & & \\
\hline & The Work Itself & 0.832 & 0.587 & 2.007 & 1 & 0.157 & 2.298 & 0.727 & 7.268 \\
\hline & $\begin{array}{c}\text { Career } \\
\text { Development }\end{array}$ & 0.257 & 0.532 & 0.232 & 1 & 0.630 & 1.293 & 0.455 & 3.671 \\
\hline & Pay & 1.097 & 0.517 & 4.509 & 1 & 0.034 & 2.995 & 1.088 & 8.246 \\
\hline \multirow[t]{4}{*}{ Common } & Intercept Term & 2.378 & 0.775 & 9.406 & 1 & 0.002 & & & \\
\hline & The Work Itself & -0.269 & 0.560 & .232 & 1 & 0.630 & 0.764 & 0.255 & 2.288 \\
\hline & $\begin{array}{c}\text { Career } \\
\text { Development }\end{array}$ & -0.450 & 0.521 & .745 & 1 & 0.388 & 0.638 & 0.230 & 1.771 \\
\hline & Pay & 0.412 & 0.494 & .698 & 1 & 0.404 & 1.510 & 0.574 & 3.973 \\
\hline \multirow[t]{4}{*}{ Very Intense } & Intercept Term & 1.035 & 0.863 & 1.440 & 1 & 0.230 & & & \\
\hline & The Work Itself & 0.229 & 0.697 & 0.108 & 1 & 0.742 & 1.257 & 0.321 & 4.928 \\
\hline & $\begin{array}{c}\text { Career } \\
\text { Development }\end{array}$ & -0.175 & 0.623 & 0.079 & 1 & 0.778 & 0.839 & 0.247 & 2.846 \\
\hline & Pay & 0.854 & 0.639 & 1.786 & 1 & 0.181 & 2.349 & 0.671 & 8.221 \\
\hline
\end{tabular}


sions about the relationship between the job satisfaction of knowledge staff and their turnover intention, whether the career development factors have impact on the turnover intention have not come to a consistent conclusion: some research has concluded that career development has no effect on turnover intention, while others think career development has certain predictive effect on the turnover intention. Based on the samples of the knowledge staff of the cultural industry of West China, the research shows that different Knowledge workers in the western region culture industry as samples of research shows that different career development satisfactions has little influence on the probability of the turnover intention, that is, the turnover intention of the knowledge employees of the cultural industry in the West region cannot be predicted by career development satisfaction.

(2) The influences of the work itself on the group with "very intense" turnover intention and that with "far from intense" group are significantly different. Compared with the group with "very intense" turnover intention, the significance of the influence probability of the satisfaction with the job itself on the group with "far from intense" turnover intention is 0.011 , which indicates that under the significance level of 0.05 , the influences of the satisfaction with the work itself on the turnover intention have statistically significant difference. According to the model, a predictor formula can be written: the number of the employees who have lower job satisfaction and choose "far from intense" turnover intention is 4.416 times as large as that of those with higher job satisfaction. In other words, in the cultural industry of the western region, the turnover intention of the knowledge staff with lower satisfaction with the work itself is not higher than that of the knowledge workers with higher satisfaction with the work itself. Some empirical research of our country indicates that the satisfaction with the work itself of knowledge staff and the turnover intention has significantly negative correlation. Nevertheless, the result of this research that adopts multiple logistic regression analysis to analyze the influence of the satisfaction with the work itself on the probability of the turnover intention is not consistent with that. On the contrary, the turnover intention of the knowledge employees in the cultural industry of the western region who have lower satisfaction with the work itself is lower than that of those with higher job satisfaction. The analysis of possible reasons will be done later.

(3) Among the groups with "very intense" turnover intention, "far from intense" turnover intention and "not very intense" turnover intention, there were significant differences in the influence of pay satisfaction. Compared with the group with "very intense" turnover intention, the significances of the influence probabilities of pay satisfaction on the groups with "far from intense" and "not very intense" turnover intention are 0.013 and 0.034 respectively. This shows that: under 0.05 significant level, compared with the group with "very intense" turnover intention, the influences of pay satisfaction on the groups with "far from intense" turnover intention and "not very intense" turnover intention and the influence on the group with "very intense" turnover intention are statistically significantly different. According to the model: the number of employees with lower pay satisfaction and "far from intense" turnover intention is 3.551 times as large as that of those with higher pay satisfaction; the "not very intense" turnover intention of the employees with lower pay satisfaction is 2.995 times than that of those with higher pay satisfaction. That is to say, the turnover intention of the employees with low pay satisfaction is far lower than that of those with high pay satisfaction, or in other words, the knowledge employees with high pay satisfaction have correspondingly higher probability of turnover intention than those with lower pay satisfaction. This is different from the existing research conclusion in China.

\subsection{Probabilistic Forecasting with the Demographic Variables}

Gender, age, educational background, professional title, monthly income level, position, years of working, the number of previous work units being considered as the covariates, establish a multiple logistic regression analysis model with the three main factors of satisfaction such as the work itself, career development and pay as explanatory variables in order to predict the probabilities of the turnover intention of different extents. The established model shows that when the above demographic variables as the covariates, only the monthly income level variable can pass the significance testing, therefore the below model building will take monthly income level as a covariate and job satisfaction factor as the explanatory variable, to forecast the probability of different turnover intentions.

"-2LL" likelihood Chi-Square value from 403.096 in initial model to 321.392 of the final model, "-2LL" value reduces by 81.704 , which indicates that the model improvement is obvious. Meanwhile, the probability sig. value of model test is 0.000 (see Table 5), which indicates that the degree of fitting of the model is good. The model regression results are as follows: 
In the multiple logistic regression model with monthly income level as the covariate, the group with "very intense" turnover intention is a control group. That is, the four groups with different levels of turnover intention are contrasted with the group of "very intense" turnover intention, to determine whether the turnover intention levels of the two groups are significant different. From the model of Table 6, the following conclusion can be drawn.

(1) The influences of the work itself on the groups with "not very intense" and "very intense" turnover intention are significantly different. Compared to the influence on the group with "very intense" turnover intention, the probability significance of the influence of the work itself on the group with "far from intense" turnover in-

Table 5. Model test.

\begin{tabular}{ccccc}
\hline Model & -2 Log Likelihood & Chi-Square & df & Sig. \\
\hline Intercept Term & 403.096 & & & \\
Final Model & 321.392 & 81.704 & 16 & 0.000 \\
\hline
\end{tabular}

Table 6. Test of the multiple logistic regression model with monthly income level added.

\begin{tabular}{|c|c|c|c|c|c|c|c|c|c|}
\hline $\begin{array}{c}\text { Turnover } \\
\text { Intention(a) }\end{array}$ & & B & Std. Error & Wald & $\mathrm{df}$ & Sig. & $\operatorname{Exp}(B)$ & \multicolumn{2}{|c|}{$\begin{array}{l}\text { 95\% Confidence } \\
\text { Interval for Exp(B) }\end{array}$} \\
\hline & & & & & & & & Lower Bound & Upper Bound \\
\hline \multirow[t]{5}{*}{ Far from Intense } & Intercept Term & -3.133 & 2.984 & 1.103 & 1 & 0.294 & & & \\
\hline & The Work Itself & 1.834 & 0.725 & 6.399 & 1 & 00.011 & 6.259 & 1.511 & 25.917 \\
\hline & $\begin{array}{c}\text { Career } \\
\text { Development }\end{array}$ & 0.078 & 0.601 & 0.017 & 1 & 0.897 & 1.081 & 0.333 & 3.508 \\
\hline & Pay & 0.360 & 0.583 & 0.381 & 1 & 0.537 & 1.433 & 0.457 & 4.496 \\
\hline & $\begin{array}{l}\text { Monthly Income } \\
\text { Level }\end{array}$ & 2.842 & 1.542 & 3.397 & 1 & 0.065 & 17.146 & 0.835 & 351.981 \\
\hline \multirow[t]{5}{*}{ Not very Intense } & Intercept Term & -4.781 & 3.004 & 2.532 & 1 & 0.112 & & & \\
\hline & The Work Itself & 1.171 & 0.730 & 2.574 & 1 & 0.109 & 3.226 & 0.771 & 13.496 \\
\hline & $\begin{array}{c}\text { Career } \\
\text { Development }\end{array}$ & -0.119 & 0.610 & 0.038 & 1 & 0.845 & .888 & 0.268 & 2.936 \\
\hline & Pay & 0.004 & 0.597 & 0.000 & 1 & 0.994 & 1.004 & 0.312 & 3.236 \\
\hline & $\begin{array}{l}\text { Monthly Income } \\
\text { Level }\end{array}$ & 3.104 & 1.543 & 4.049 & 1 & 0.044 & 22.283 & 1.084 & 458.088 \\
\hline \multirow[t]{5}{*}{ Common } & Intercept Term & -4.201 & 2.978 & 1.991 & 1 & 0.158 & & & \\
\hline & The Work Itself & .114 & 0.707 & .026 & 1 & 0.872 & 1.121 & 0.280 & 4.481 \\
\hline & $\begin{array}{c}\text { Career } \\
\text { Development }\end{array}$ & -0.795 & 0.596 & 1.778 & 1 & 0.182 & 0.452 & 0.140 & 1.453 \\
\hline & Pay & -0.512 & 0.565 & 0.823 & 1 & 0.364 & 0.599 & 0.198 & 1.812 \\
\hline & $\begin{array}{l}\text { Monthly Income } \\
\text { Level }\end{array}$ & 2.843 & 1.539 & 3.413 & 1 & 0.065 & 17.173 & 0.841 & 350.612 \\
\hline \multirow[t]{5}{*}{ Very Intense } & Intercept Term & -4.798 & 3.113 & 2.376 & 1 & 0.123 & & & \\
\hline & The Work Itself & 0.652 & 0.813 & 0.643 & 1 & 0.423 & 1.919 & 0.390 & 9.452 \\
\hline & $\begin{array}{c}\text { Career } \\
\text { Development }\end{array}$ & -0.484 & 0.686 & 0.497 & 1 & 0.481 & 0.60 .7 & 0.161 & 2.365 \\
\hline & Pay & 0.054 & 0.700 & 0.006 & 1 & 0.938 & 1.056 & 0.268 & 4.160 \\
\hline & $\begin{array}{l}\text { Monthly Income } \\
\text { Level }\end{array}$ & 2.639 & 1.560 & 2.860 & 1 & 0.091 & 13.994 & 0.658 & 297.799 \\
\hline
\end{tabular}


tention is 0.011 , which shows that: under 0.05 significance level, the impact probability of the work itself on the group with "far from intense" turnover intention reaches statistical significance. The prediction formula, written according to the results of the logistics model: the number of the employees with low satisfaction with the work itself who choose "far from intense" turnover intention is 6.259 times than that of those with high satisfaction with the work itself. In other words, after gender, age, educational background, professional title, monthly income level, position, years of working and the number of previous work units being considered as the covariates, none of the factors in the covariates has significantly different influences on the turnover intentions of the two groups, i.e., the probability of the knowledge employees with low satisfaction with the work itself having "far from intense" turnover intention is much higher than those with high satisfaction with the work itself.

(2) Compared with the group with "very intense" turnover intention, the probability of the influence of the monthly income level on the group with "not very intense" turnover intention is significantly different, while the influence probability of the work itself, career development and compensation on the turnover intention of this group is not differential. The influence significance value of monthly income level on the group with "not intense" turnover intention is 0.044 , which shows that: under significance level of 0.05 , the impact probability of monthly income level on the group with "not very intense" turnover intention is very significant. The prediction formula can be written: the number of employees with low monthly income level who choose "not very intense" turnover intention is 22.283 times that of those with high monthly income level. That is to way, the intention of the employees with low monthly income level in the cultural industry of the western region is much higher than that of those with high income level.

(3) such covariates as gender, age, educational background, professional title, income level, position, working years, the number of previous work units being added, the influences of the work itself, career development and compensation satisfaction on turnover intention, compared to the group with "very intense" turnover intention, make little difference to the groups with "common" and "very intense" turnover intention. That is to say, after the above covariates being added, the work itself, career development and compensation satisfaction had no predictability on the turnover intention of the groups with "common", "relatively intense" and "very intense".

\section{Result Analysis and Inspiration}

\subsection{Result Analysis}

(1) This study has found that, for the knowledge-type employees in the culture industry of the western region, career development cannot predict the turnover intention. This empirical result is different from the existing research results on the correlation between the job satisfaction and turnover intention of knowledge employees. It is probably because that the respondents of this paper are different from previous objects of study. Generally, the objects of study who could lead to the conclusion that the career development and turnover intention are negatively correlated are teachers in universities and colleges as well as staff in science and technology institutions. With higher professional knowledge level, higher requirements on specialty accuracy, and more support from organizational and external environment for their career development, they have stronger pursuit of career development, compared to the knowledge employees of cultural industry. As it were, career development is the lifeline of this group of knowledge staff. Comparatively speaking, eagerness degree of the knowledge staff in cultural industry for career development is lower. Therefore, we should be very prudent while using satisfaction of career development to predict the turnover intention of the knowledge staff in the culture industry of the western areas.

(2) Another conclusion of this study is also very interesting: the turnover intention of the knowledge employees with low satisfaction with the job itself is lower that with high satisfaction with the work itself; and those with high monthly income level have stronger turnover intention. Two reasons may explain this phenomenon. First, the objects of study work in the cultural industry of western region where the market development level is relatively low. Most knowledge employees studied by existing research of China are from eastern region or IT industry with higher marketization level. In our country, however, the reform in the fields of cultural undertakings is in progress and the marketization levels of various factors in the fields are under way. The Western China, the degree of development of the human capital market of relatively lagging behind, has fewer available work opportunities and lower human capital flow smoothness, which causes that some employees have low satisfaction with the work itself and compensation but are unwilling to quit. Second, the high income group with abundant human capital in the cultural industry of western region has the ability to seek the return of value 
matching that; once the external environment is suitable, they can get better job opportunities, so they tend to have higher turnover intention. In recent years, the booming cultural industry in East China has provided more and better job opportunities, which has contributed stronger turnover intention of the knowledge staff with higher income in the cultural industry of West China. This requires further in-depth discussion in future research; besides job satisfaction, the demission behaviors need to be discussed from such variables as external job opportunities.

(3) In the probability model of job satisfaction affecting turnover intention, after the 8 covariates being added, all statistical characteristics but monthly income level do not have significant influences on turnover intention. This conclusion is also different from some existing analysis results. The value of this research conclusion lies in that it does not simply discuss the differences of a certain characteristic in terms of work satisfaction, but combine various characteristics with job satisfaction to build an integrated model, improving the synthetic prediction accuracy of various characteristics and able to "target" at the group with stronger turnover intention more accurately. If we studied the differences of one of the variables with job satisfaction Under the probability level of $95 \%$, the synthetic judgment accuracy of the 8 covariates is only $0.66(0.95 \times 0.95 \times 0.95 \times 0.95 \times 0.95$ $\times 0.95 \times 0.95 \times 0.95=0.66$ ), while the overall judgment accuracy of the model we built on the 8 characteristics as covariates is $95 \%$. It may also be the reason why this research conclusion is different from some existing analysis results. Moreover, this analysis conclusion is more valuable in practical operation. In practice, it is necessary to accurately adopt the characteristics provided by the analysis conclusion to judge the probability of the turnover intention; if the analysis conclusion based on a singular factor is used to an individual with different characteristics in one, it is difficult to reach judgment with high accuracy. The comprehensive model this paper has built can accurately point out that income level is an important indicator to judge the probability of turnover intention, while other characteristics are not significant.

\subsection{Inspiration}

(1) With the knowledge workers in the culture industry of Western China as the objects of study, the empirical research conclusion on the relationship between job satisfaction and turnover intention is not exactly the same as the existing analysis conclusions. This suggests the complexity of the correlation between the job satisfaction and turnover intention of knowledge-based employees, which can't be simply predicted with the relation model of between work satisfaction and turnover intention of the knowledge employees from other countries, industries or regions. Instead, the characteristics of knowledge employees in cultural industry different from those of employees in universities, colleges, research institution and IT industry must be considered and further researched, so as to improve the accuracy of predicting the turnover intention with work satisfaction in practical operation.

(2) The turnover intention of the knowledge employees with low satisfaction with the work itself is not higher than that of the knowledge workers with high satisfaction with the work itself, which is against the existing conclusion in the academic field. This reminds us that there are some "zombie" knowledge employees in the cultural industry of western region, and their low work satisfaction will adversely affect the creativity at work. This group of knowledge employees is not the focus of turnover intention forewarning management, but the main incentive objects.

(3) In current practice, the preferential tool of preventing the drain of knowledge staff in the cultural industry of western region is high salary, and turnover forecasting management of the group with higher pay is neglected. Our research has found that the knowledge employees with high pay satisfaction and income level have higher probability of turnover intention than those with low pay satisfaction and income level. This indicates that the latter group should be the main objects of turnover forecasting management in the cultural industry of western region. Meanwhile, tools other than "high pay" should be discovered to effectively forecast the turnover intention of the group with high income level and pay satisfaction.

\section{References}

[1] Porter, L.W. and Steers, R.M. (1973) Organational Work and Personal Factors in Turnover and Absenteeism. Psychological Bulletin, 80, 151-176. http://dx.doi.org/10.1037/h0034829

[2] Tsui, A.S., Egan, T.D. and O’Reilly III, C.A. (1992) Being Different: Relational Demography and Organizational Attachment. Administrative Science Quarterly, 37, 549-579. http://dx.doi.org/10.2307/2393472 
[3] Peterson, R. (1994) A Meta-Analysis of Cronbach’s Coefficient Alpha. Journal of Consumer Research, 21, 381-391. http://dx.doi.org/10.1086/209405 